\title{
Prevalence and correlates of malnutrition among hemodialysis patients at hebron governmental hospital, Palestine: cross- sectional study
}

Manal Badrasawi $1^{*}$, Souzan Zidan², Israa Sharif ${ }^{3}$, Juliana Qaisiyha ${ }^{3}$, Sanabel Ewaida ${ }^{3}$, Tala Jaradat ${ }^{3}$ and Yasmeen Samamra ${ }^{3}$

\begin{abstract}
Background: Malnutrition is a usually observed condition among patients on hemodialysis and is considered one of sturdiest indicators of mortality and morbidity.

Objectives: The current study was performed to assess the prevalence of malnutrition, to verify whether functional status is associated with malnutrition, and to explore the probable factors related to malnutrition among a sample of hemodialysis patients at Hebron Governmental Hospital in West Bank, Palestine.

Methods: A cross-sectional study was conducted on hemodialysis patients in Hebron Governmental Hospital at Hebron city/Palestine. An interview-based questionnaire was used to obtain information related to sociodemographics, dialysis, medical history, lifestyle, anthropometric measurements, dietary data, and functional status. Renal inpatient screening tool (renal iNUT) was also utilized to screen hemodialysis patients for malnutrition. Furthermore, biochemical tests were obtained during the study period from medical files of the studied patients.

Results: A total of 153 patients, having a mean age of $50.1 \pm 16.6$ years, were involved in the final analysis. The results indicated that the prevalence of high risk of malnutrition (45.4\%). Moreover, high risk of malnutrition was significantly associated with occupation, and walking. It was further found that patients with high risk of malnutrition are more likely to had osteoporosis, unable to ambulate, didn't feel that the amount of food they eat is enough. Our findings also figured out that some complications during hemodialysis session (e.g., headache, nausea, hypotension) and some hemodialysis side effects (e.g., itching, access site complication) were significantly correlated to malnutrition.
\end{abstract}

\footnotetext{
* Correspondence: m.badrasawi@najah.edu

'Department of Nutrition and Food technology, Faculty of Agriculture and

Veterinary medicine, An-Najah National University, Nablus, West Bank,

Palestine

Full list of author information is available at the end of the article
}

(c) The Author(s). 2021 Open Access This article is licensed under a Creative Commons Attribution 4.0 International License, which permits use, sharing, adaptation, distribution and reproduction in any medium or format, as long as you give appropriate credit to the original author(s) and the source, provide a link to the Creative Commons licence, and indicate if changes were made. The images or other third party material in this article are included in the article's Creative Commons licence, unless indicated otherwise in a credit line to the material. If material is not included in the article's Creative Commons licence and your intended use is not permitted by statutory regulation or exceeds the permitted use, you will need to obtain permission directly from the copyright holder. To view a copy of this licence, visit http://creativecommons.org/licenses/by/4.0/ The Creative Commons Public Domain Dedication waiver (http://creativecommons.org/publicdomain/zero/1.0/) applies to the data made available in this article, unless otherwise stated in a credit line to the data. 
Conclusions: A high prevalence of malnutrition was revealed among hemodialysis using renal iNUT screening tool. Improving nutritional assessment methods for patients on hemodialysis is highly needed. Findings reveals that risk of malnutrition is associated with multiple factors such as osteoporosis, occupation, walking, ability to ambulate, certain complication during hemodialysis session, and some hemodialysis side effects. Further studies are highly recommended.

Keywords: Prevalence, Hemodialysis, Malnutrition, Indicators

\section{Background}

The incidence of chronic kidney disease is growing all over the world. Universally, patients having chronic kidney disease keeps to increase at the rate of $7 \%$ yearly [1]. The most popular reasons for chronic kidney disease are hypertension, glomerulonephritis, and diabetes mellitus. Jointly, these result in roughly $75 \%$ of overall adult cases [2]. Chronic kidney disease is a common health issue in the Palestinian community, as it is considered the ninth leading cause of death in Palestine by $3.2 \%$ [3]. In 2019, the total number of functional hemodialysis centers in west bank area was 11 centers, with 219 devices for industrial kidney. According to the last Palestinian health annual report in 2019, the number of patients on regular dialysis in West Bank area was 1,545 cases [3].

Protein-energy wasting (PEW) is a relatively prevalent health issue among patients undergoing hemodialysis (HD) therapy [4]. Since the existence of protein-energy wasting is known to be one of the sturdiest indicators of mortality and morbidity in hemodialysis patients, it is crucial that dietitians precisely assess malnutrition in these patients $[4,5]$. Malnutrition in patients undergoing hemodialysis therapy usually results from decreased appetite, drug-related factors, and a very limited diet [6, 7].

The Renal Inpatient Nutrition Screening Tool (Renal iNUT) was evolved for the specialist renal ward at St George's Hospital (SGH), as a result of a scarceness of a validated renal-specific nutrition screening tool for renal failure patients. The scoring system of iNUT was according to Malnutrition Universal Screening Tool because of nursing staff intimacy with the general tool [8].

There is evidence that hemodialysis therapy can elevate energy expenditure by $20 \%$ in a hemodialysis session [9]. Other factors also can elevate energy expenditure in patients undergoing hemodialysis such as abnormal hormone levels involving insufficient production of testosterone in both gender [10], growth hormone and insulin resistance [11], persistent inflammation [12], and low levels of triidothyroid [13]. Acidosis, which is prevalent metabolic derangement in patients undergoing hemodialysis, suppresses protein synthesis and quickens protein degeneration [14].

Hemodialysis therapy is usually associated with a large number of comorbidities including; secondary hyperparathyroidism, diabetes, infectious diseases, gastrointestinal disorders, and diabetes mellitus [15].

The inception of hemodialysis is linked with a decrease in functional status among elderly [16], resulting in a vicious cycle of decreased consumption of food, because of reduced physical function and loss of appetite, at last patients' nutritional status of get worse [17]. A former study indicated that reduced ability to do daily living activities is correlated with increased risk of mortality among patients on hemodialysis [18].

It is highly recommended to use both physical and nutritional therapy in order to enhance the outcomes and experience of patients on hemodialysis [19]. Precocious recognition of hemodialysis patients with decreased nutritional status through proper intervention, along with the utilization of a proper therapeutic intervention is considered a fundamental action to avoid the progression of severe malnutrition [20].

The main purpose of this cross-sectional study was to determine the prevalence of malnutrition among a sample of hemodialysis patients at Hebron governmental hospital, Palestine. Other purposes were verifying whether functional status of patients on hemodialysis is associated with malnutrition, and determining factors predicting malnutrition in hemodialysis patients. In general, this study will assist in applying appropriate interventions which aims to attain an optimal nutritional status in a population of hemodialysis patients.

\section{Methodology}

Study design, settings, and population

This cross-sectional design study was performed a representative sample of Palestinian hemodialysis patients in Hebron Governmental Hospital in Hebron city, Palestine.

\section{Sample size}

The sample size was estimated depending on the number of hemodialysis patients in each unit. $G$ power software for sample size calculation was used with $5 \%$ margin of error and $95 \%$ confidence level. The sampling method used in the study is purposive sampling [21]. The inclusion criteria were cancer patients who have finished their treatment before minimum 6 month and they have no cancer recurrence during the data collection, patients (over 18 years old) under dialysis therapy, 
patients were willing to participate and to provide all the required data. The exclusion criteria were cancer patients who are currently undergoing chemotherapy, radiotherapy treatment, pregnant women, patients with communication problems, mental problem or feel tired during the hemodialysis prevent them to answer the questions.

\section{Ethical consideration}

The study protocol, which has a reference number of KA/41/2021, was approved by the Deanship of Scientific Research Ethical Committee at Palestine Polytechnic University committee. Permissions and approval to conduct the study were obtained from the Palestinian Ministry of Health. Written informed consent was also obtained from each participant.

\section{Data collection and research tool}

Interview based pre-tested questionnaire was administered to hemodialysis patients during hemodialysis sessions. Data collection started on August 2020 and ended on November 2020 by a group of four nutritionists. Hemodialysis patients were briefed on the objective of the study, then, the questionnaires were administrated upon verbal consent from the patients. The collected data included sociodemographic data (e.g., age, gender, area of living and educational and economic status), medical history and laboratory values, anthropometric measurements, dialysis-related data, hemodialysis side effects, clinical assessment, and functional status.

\section{Demographics, and Lifestyle Habits}

Questions regarding demographic data, including patient age, gender, marital status, and educational level, were asked for each patient. Data about lifestyle habits (e.g., smoking, frequency of smoking per day, doing exercises, walking, and duration of watching $\mathrm{TV}$ and sleeping) were elicited from the patients.

\section{Medical History, and Laboratory Values}

Medical history including self-reported questions about previous surgery, and the presence of comorbidities (e.g., hypertension, angina, heart disease, diabetes, asthma, chronic obstructive pulmonary disease, osteoporosis, arthritis, irritable bowel syndrome, gastric esophageal reflux disease, peptic ulcer). Blood tests, including serum albumin, total protein, potassium, sodium, phosphorous, calcium, and hemoglobin, were also obtained from patients' records.

\section{Hemodialysis-related data}

In this part of the questionnaire, the patients were asked numerous questions including; the number of months on hemodialysis, number of hemodialysis sessions per week, duration of hemodialysis session, and nutrition consultation.

\section{Hemodialysis side effects}

Data regarding the experienced complications during hemodialysis session (nausea, vomiting, headache, cramps, and hypotension), and side effects of hemodialysis (e.g., muscle cramps, headache, itching, sleeping disruptions, bone disease, hypertension, fluid overload, pericarditis, and joint diseases) were elicited from patients.

\section{Nutritional status assessment \\ Nutrition intervention}

Questions regarding nutrition consultation, the source of nutrition information, and whether they were given a specialized course in renal nutrition were asked in this part of the questionnaire.

\section{Malnutrition screening tool}

Renal inpatient nutrition screening tool (renal iNUT), a validated renal-specific nutrition screening tool, used to evaluate malnutrition. The renal iNUT includes questions on height, measured weight, estimated weight loss, body mass index (BMI), renal-specific details on weight, the use of nutritional supplements, appetite, and food intake. Based on these questions every patient was given a score that reflect his nutritional status as follows: high (score $\geq 2)$, medium $($ score $=1)$, and low $($ score $=0)$ of malnutrition with proper action plan [8].

\section{Anthropometric measurements}

Anthropometric indices including (height, and weight) were used to examine the nutritional status of hemodialysis patients. Body weight was weighted pre-dialysis and postdialysis according to the standard anthropometric procedures described by Lee \&Nieman [22]; the participants were also recorded pre-dialysis. Body mass index was calculated as (body in kilogram divided by height squared in meter $(\mathrm{kg} / \mathrm{m} 2)$, thereafter classified according to WHO cut off points [23].

\section{Clinical signs}

Data regarding weight changes during the last six months, the presence of gastrointestinal symptoms, loss of subcutaneous fat (under eye, triceps, biceps), and muscle wasting (deltoid muscle), presence of ascites or edema were collected in this section of the questionnaire.

\section{Dietary practices}

Dietary practices questions were designed to see dietary changes between non-dialysis days and dialysis days. Questions regarding the number of total meals, main meals and snacks per day, skipping meals, patient's 
appetite, diet changes during dialysis days, his/her perception about the quantity of food that he/she eat, and the changes in the size of food he/ she eat in dialysis days were included in this section.

\section{Functional status assessment}

The questionnaire included three self-reported questions designed to assess poor functional status, which is realized by the presence of any of the three co-morbid situations as assigned in form CMS-2728- (a) inability to ambulate, (b) need of support with daily activities or (c) inability to transfer [24].

\section{Statistical analysis}

The Statistical Package for the Social Sciences SPSS TM, version 21 was used to analyze the collected data, $5 \%$ alpha level and $80 \%$ power was considered in all of the statistical tests. Continuous variables were assessed for normality of distribution graphically and via the Shapiro-Wilk Test. Descriptive analysis including the means and the standard deviations were used to analyze the continuous data, the categorical data were described in percentages and frequencies. The prevalence of malnutrition was presented in percentages. Kruskal-Wallis test and one-way ANOVA test were used to determine the relationship between continuous variables and Chi-square test was used to determine the relationship between categorical variables. Logistic regression was performed to estimate the magnitude of relationship between the response variable of malnutrition risk and the explanatory variables (sociodemographic data, medical history, hemodialysis complications, dietary practices). Hosmer-Lemeshow goodness of fit test was done to assess how well the model fit the data.

\section{Results}

\section{Patients' recruitment}

Figure 1 shows patients' recruitment steps, among the total of 280 participants, only 152 patients were included in the final analysis: $48.0 \%(n=73)$ females and $52.0 \%$ $(n=79)$ males. The other patients were excluded mainly due to missing data.

\section{Patients' Sociodemographic Characteristics}

The mean age of hemodialysis patients was $50.1 \pm 16.6$ years, ranged from 18 to 85 years old. The analysis revealed that most of the enrolled patients $76.3 \%(n=116)$ were married, while the other $23.7 \%(n=36)$ were not married "divorced, single, widow". Nearly half of the patients $47.4 \%(n=72)$ received a primary education, and only $3.9 \%(n=6)$ of patients did not receive a formal education. It also revealed that nearly half of the nurses $53.3 \%(n=81)$ were living in the cities, while the rest $46.7 \%(n=71)$ were living either in villages or camps. The majority of participants $96.7 \%(n=147)$ were living with their families (e.g., spouse/siblings/parents), while only $3.3 \%(n=5)$ were living alone.

\section{Patients' Lifestyle}

The findings showed that most of the participants $(81.6 \%)$ stated that they are non-smokers. It was also found that the participants have a mean time of watching television by $2.2 \pm 3.7 \mathrm{~h}$ per day and have a mean sleeping time of $7.1 \pm 1.3 \mathrm{~h}$ per day. Moreover, nearly $33.6 \%(n=51)$ of the participants walk, whilst nearly half of participants $48 \%(n=73)$ don't walk. Furthermore, a low percentage of patients $2.0 \%(n=3)$ reported that they do sport either at home or at gym with a mean frequency of $2.9 \pm 0.4$ times per week.

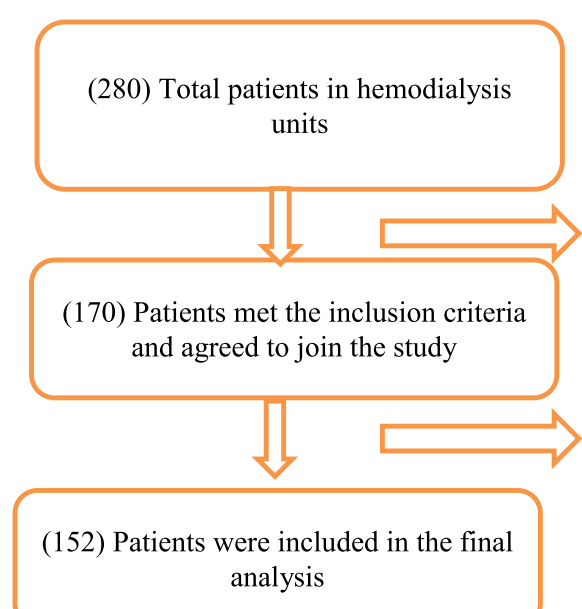

110 patients were excluded due to: -

- Patients were tired to give the data

- Patients refused to participate

- Patients with mental problems

- Pregnant women

18 patients were excluded due to missed data.

Fig. 1 Patients' recruitment chart 


\section{Medical history}

The results of medical history revealed that a high percentage of patients were having a hypertension $80.9 \%$ $(n=123)$, followed by diabetes mellitus $46.7 \%(n=71)$. While a small percentage of patients reported that they had chronic obstructive pulmonary disorder, asthma, and angina by $12.5 \%(n=19), 12.5 \%(n=19)$, and $8.6 \%$ $(n=13)$, respectively. Furthermore, it observed that the vast majority of patients $92,8 \%(n=129)$ stated that they had previously made a surgical operation.

\section{Hemodialysis-related data}

The findings revealed that the mean months on hemodialysis was $45.7 \pm 33.5$ months, the mean number of hemodialysis session is $2.7 \pm 0.5$ session per week, and the mean length of hemodialysis session is $2.9 \pm 0.6 \mathrm{~h} /$ session. Furthermore, only nine patients $5.9 \%$ had a kidney transplantation surgery.

\section{Hemodialysis side effects}

Table 1 shows that the most common complication during dialysis session was hypotension by $34.9 \%(n=53)$, then headache by $30.9 \%(n=46)$, while the least noticed complication during the session was vomiting by $11.8 \%$ $(n=18)$. And as we can see in Table 1 , the most noticed side effects of hemodialysis experienced by the patients were headache, sleeping distributions, and itching by $84.9 \%(n=62), 80.8 \%(n=59)$, and $65.8 \%(n=48)$, respectively. On the otherhand, a minority of patients have stated that they were experiencing pericarditis by $6.8 \%$ $(n=5)$ as dialysis side effect.

\section{Nutritional status assessment Nutrition intervention}

Our data analysis showed that minority of patients $16.4 \%(n=5)$ received nutrition consultation before hemodialysis sessions, $24.3 \%(n=37)$ received consultation during hemodialysis session, and $13.3 \%(n=20)$ received consultation post hemodialysis session. The findings also showed that most patients $79.4 \%(n=112)$ get the nutrition information from health team workers (e.g., doctors and nurses), followed by nutritionists $11.3 \%(n=16)$, while the rest get the information from other sources "e.g., internet, Facebook, friends". Furthermore, only $7.9 \%(n=12)$ of patients stated that they were given a specialized course in renal nutrition.

\section{Malnutrition risk}

Our statistical analysis showed that the proportion of patients who unintentionally lost weight was significantly higher in females $40.3 \%(n=29)$ than in males $24.7 \%$ $(n=19)$. Furthermore, a high percentage of patients $87.5 \%(n=133)$ who had an acceptable BMI while only $12.5 \%(n=19)$ of patients looked malnourished, which means that the BMI is lower than $20 \mathrm{~kg} / \mathrm{m}^{2}$. It also found that the percentage of females on hemodialysis $8.2 \%(n=6)$ who take nutritional supplements were significantly higher in comparison to males on hemodialysis

Table 1 Hemodialysis side effects \&its complications during hemodialysis session according to gender

\begin{tabular}{|c|c|c|c|c|c|c|c|}
\hline \multirow[t]{2}{*}{ Side effects } & \multicolumn{2}{|c|}{ Total } & \multicolumn{2}{|c|}{ Males } & \multicolumn{2}{|c|}{ Females } & \multirow[t]{2}{*}{$p$-value } \\
\hline & $n$ & $\%$ & $n$ & $\%$ & $n$ & $\%$ & \\
\hline Muscle Cramps & 77 & 50.7 & 41 & 51.9 & 36 & 49.3 & 0.438 \\
\hline Headache & 97 & 63.8 & 35 & 44.3 & 62 & 84.9 & $0.000^{*}$ \\
\hline Itching & 93 & 61.2 & 45 & 57.0 & 48 & 65.8 & 0.172 \\
\hline Sleeping distributions & 110 & 72.4 & 51 & 64.6 & 59 & 80.8 & 0.019 \\
\hline Bone diseases & 58 & 38.2 & 21 & 26.6 & 37 & 50.7 & $0.002^{*}$ \\
\hline Hypertension & 97 & 63.8 & 51 & 64.6 & 46 & 63.0 & 0.488 \\
\hline Fluid overload & 93 & 61.2 & 46 & 58.2 & 47 & 64.4 & 0.271 \\
\hline Pericarditis & 15 & 9.9 & 10 & 12.7 & 5 & 6.8 & 0.177 \\
\hline Joint diseases & 40 & 26.3 & 15 & 19.0 & 25 & 34.2 & $0.025^{*}$ \\
\hline Complications at the access site & 40 & 26.3 & 21 & 26.6 & 19 & 26.0 & 0.543 \\
\hline Emotional distress & 93 & 61.2 & 45 & 57.0 & 48 & 65.8 & 0.172 \\
\hline \multicolumn{8}{|c|}{ Complications during hemodialysis session } \\
\hline Nausea & 11 & 13.9 & 18 & 24.7 & 29 & 19.1 & 0.183 \\
\hline Vomiting & 7 & 8.9 & 11 & 15.1 & 18 & 11.8 & 0.319 \\
\hline Headache & 14 & 17.7 & 32 & 43.8 & 46 & 30.3 & $0.000^{*}$ \\
\hline Cramps & 14 & 17.7 & 13 & 17.8 & 27 & 17.8 & 0.525 \\
\hline Hypotension & 24 & 30.4 & 29 & 39.7 & 53 & 34.9 & 0.141 \\
\hline
\end{tabular}

${ }^{*}$ significant at $p<0.05$ using chi-square test 
$0.0 \%(n=0)$. Moreover, the analysis revealed that patients' food intake was similar to usual days in nearly half of the patients $50 \%(n=76)$. Furthermore, the patients' appetite was significantly worse in nearly $61.6 \%$ $(n=45)$ females compared to males $44.3 \%(n=35)$. Figure 2 divided patients into three groups based on renal iNUT. Nearly half of the patients $45.4 \%(n=69)$ patients had a high risk of malnutrition, $36.8 \%(n=56)$ patients had a low risk of nutrition, and only $17.8(n=27)$ patients had no risk of malnutrition.

\section{Anthropometric measurements}

Generally, $37.5 \%(n=57)$ of the participants had normal weight, $26.3 \%(n=40)$ were overweight, $28.9 \%(n=44)$ were obese, whilst only eleven participants $7.2 \%$ were underweight.

\section{Biochemical data}

The analysis revealed that the patients had a mean total protein of $6.7 \pm 0.7 \mathrm{~g} / \mathrm{dL}$, a mean serum potassium level of $4.9 \pm 1.0 \mathrm{mEq} / \mathrm{L}$, a mean serum albumin level of $3.9 \pm$ $0.6 \mathrm{~g} / \mathrm{dL}$, a mean serum sodium level of $133.4 \pm 10.3$ $\mathrm{mEq} / \mathrm{dL}$, a mean serum phosphorous level of $5.1 \pm$ $1.4 \mathrm{mg} / \mathrm{dL}$, a mean serum calcium level of $8.2 \pm 1.1 \mathrm{mg} /$ $\mathrm{dL}$, and a mean hemoglobin level of $9.6 \pm 5.3 \mathrm{~g} / \mathrm{dL}$.

\section{Clinical signs}

The majority of patients $82.9 \%(n=126)$ stated that they suffered from gastrointestinal symptoms, (e.g., diarrhea, nausea, vomiting, anorexia). It also found that the loss of subcutaneous fat under eyes was normal in most patients by $82.2 \%(n=125)$. Furthermore, it observed that $82.2 \%(n=125)$ of patients had a normal wasting in deltoid muscle. Seventy-five patients $49.3 \%$ suffered from normal oedema. Nearly half of the patients $53.9 \%$ ( $n=$ 82) stated they had normal ascites. Our findings revealed that about half of the participants $45.0 \%(n=67)$ lost less than $5 \%$ of their weight during the last six months (Table 2).

\section{Dietary practices}

Nearly $66.4 \%(n=101)$ of patients were used to consume the same number of main meals and snack in both normal days and dialysis days. While only $15.8 \%(n=$ 24) of patients ate more meals (main meals and snacks) during non-dialysis days compared to dialysis days. About half of the participants $52.6 \%(n=80)$ were used to ate less than 3 main meals in a dialysis day compared to regular day. The vast majority of patients $94.1 \%$ ( $n=$ 143) stated that they consume less than three snacks in a dialysis day compared to a regular day. And only $2.6 \%$ $(n=4)$ of participants were used to consume three snacks in dialysis days in comparison to regular days. In addition, our results reveals that the percentage of patients, who usually skip their meals, is almost $40.1 \%$ $(n=61)$, and about $20.4 \%(n=31)$ of patients stated that they do not usually skip their meals. Furthermore, $59.2 \%(n=90)$ of patients reported that they skip the same number of snacks in dialysis days compared to non-dialysis days.

The proportion of patients, who felt that the amount of food they eat is enough, is about $65.1 \%(n=99)$, whereas $23 \%(n=35)$ of patients felt that the amount of food they eat is not enough. Nighty-nine patients $66.4 \%$ also stated that the proportion of food they consume in dialysis days is the same as in non-dialysis days, whereas sixteen patients $10.7 \%$ reported that the portion of food they eat in dialysis days is smaller compared to the portion of food they eat in normal days. Moreover, our analysis found that nearly half of patients $47.4 \% \quad(n=72)$ didn't lose their appetite after initiation of hemodialysis sessions. Half of the patients $50.3 \%(n=76)$ reported

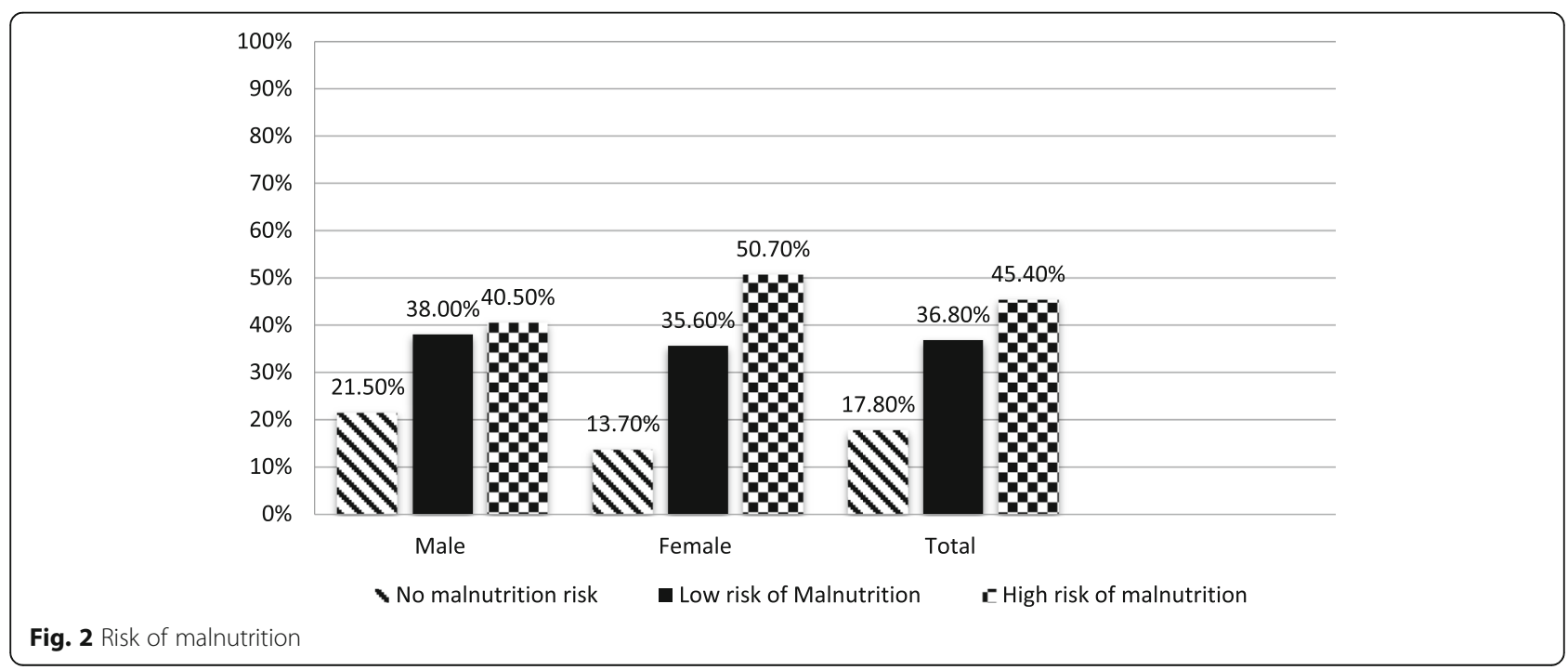


Table 2 Clinical signs of patients

\begin{tabular}{|c|c|c|c|c|c|c|c|c|}
\hline \multirow[t]{2}{*}{ Variable } & & \multicolumn{2}{|c|}{ Total } & \multicolumn{2}{|c|}{ Males } & \multicolumn{2}{|c|}{ Females } & \multirow[t]{2}{*}{$p$-value } \\
\hline & & $\mathrm{n}$ & $\%$ & $\bar{n}$ & $\%$ & $\bar{n}$ & $\%$ & \\
\hline \multirow[t]{3}{*}{ Gastrointestinal symptoms } & Infrequent & 126 & 82.9 & 62 & 78.5 & 64 & 87.7 & 0.258 \\
\hline & $<2 \mathrm{~d} /$ wks & 22 & 14.5 & 15 & 19.0 & 7 & 9.6 & \\
\hline & $>2 \mathrm{~d} / \mathrm{wks}$ & 4 & 2.6 & 2 & 2.5 & 2 & 2.7 & \\
\hline \multirow[t]{3}{*}{ Loss of subcutaneous fat under eyes } & Normal & 125 & 82.2 & 63 & 79.7 & 62 & 84.9 & 0.562 \\
\hline & Mild & 0 & 0.0 & 0 & 0.0 & 0 & 0.0 & \\
\hline & Severe & 27 & 17.8 & 16 & 20.3 & 11 & 15.1 & \\
\hline \multirow[t]{3}{*}{ Wasting in deltoid muscle } & Normal & 125 & 82.8 & 66 & 84.6 & 59 & 80.8 & 0.344 \\
\hline & Mild & 0 & 0.0 & 0 & 0.0 & 0 & 0.0 & \\
\hline & Severe & 26 & 17.2 & 12 & 15.4 & 14 & 19.2 & \\
\hline \multirow[t]{3}{*}{ Oedema } & Normal & 75 & 49.3 & 37 & 46.8 & 38 & 52.1 & 0.407 \\
\hline & Mild & 59 & 38.8 & 30 & 38.0 & 29 & 39.7 & \\
\hline & Severe & 18 & 11.8 & 12 & 15.2 & 6 & 8.2 & \\
\hline \multirow[t]{3}{*}{ Ascites } & Normal & 82 & 53.9 & 47 & 59.5 & 35 & 47.9 & 0.320 \\
\hline & Mild & 46 & 30.3 & 22 & 27.8 & 24 & 32.9 & \\
\hline & Severe & 24 & 15.8 & 10 & 12.7 & 14 & 19.2 & \\
\hline \multirow[t]{3}{*}{ Weight changes during the last six months } & $<5 \%$ & 67 & 45.0 & 36 & 46.8 & 31 & 43.1 & 0.073 \\
\hline & $5-10 \%$ & 34 & 22.8 & 22 & 28.6 & 12 & 16.7 & \\
\hline & $>10 \%$ & 48 & 32.2 & 19 & 24.7 & 29 & 40.3 & \\
\hline
\end{tabular}

$d$ day; wks weeks

that their appetite in dialysis days was the same as in normal days, while twenty-seven patients $17.9 \%$ indicated that their appetite in dialysis days was lower compared to their appetite during normal days. The vast majority of patients $74.3 \%(n=113)$ have consumed full liquid diet during hemodialysis diet.

\section{Functional status assessment}

Table 3 elucidates that hemodialysis patients were unable to ambulate, to transfer, and to do daily activities by
$63.8 \% \quad(n=97), \quad 59.2 \% \quad(n=90)$, and $48.7 \% \quad(n=74)$, recpectively.

\section{Association of demographic and lifestyle with malnutrition risk}

Table 4 presents the relationship of malnutrition with sociodemographic characteristics among hemodialysis patients. We observed that malnutrition is associated with working status before and after dialysis. And it also noticed that malnutrition is more common among patients who don't walk (57.5\%) compared to those

Table 3 Patients' functional status

\begin{tabular}{|c|c|c|c|c|c|c|c|}
\hline \multirow[t]{2}{*}{ Variables } & & \multicolumn{2}{|c|}{$\begin{array}{l}\text { Males } \\
(n=79) \\
\end{array}$} & \multicolumn{2}{|c|}{$\begin{array}{l}\text { Females } \\
(n=73)\end{array}$} & \multicolumn{2}{|c|}{$\begin{array}{l}\text { Total } \\
(n=152)\end{array}$} \\
\hline & & $\mathbf{N}$ & $\%$ & $\mathbf{N}$ & $\%$ & $\mathbf{N}$ & $\%$ \\
\hline \multirow[t]{3}{*}{ Ability to ambulate } & Yes & 21 & 26.6 & 26 & 35.6 & 47 & 30.9 \\
\hline & Sometimes & 4 & 5.1 & 4 & 5.5 & 8 & 5.3 \\
\hline & No & 54 & 68.4 & 43 & 58.9 & 97 & 63.8 \\
\hline \multirow[t]{3}{*}{ Ability to transfer } & Yes & 24 & 30.4 & 29 & 39.7 & 53 & 34.9 \\
\hline & Sometimes & 5 & 6.3 & 4 & 5.5 & 9 & 5.9 \\
\hline & No & 50 & 63.3 & 40 & 54.8 & 90 & 59.2 \\
\hline \multirow[t]{3}{*}{ Ability to do daily activities } & Yes & 30 & 38.0 & 30 & 41.1 & 60 & 39.5 \\
\hline & Sometimes & 11 & 13.9 & 7 & 9.6 & 18 & 11.8 \\
\hline & No & 38 & 48.1 & 36 & 49.3 & 74 & 48.7 \\
\hline
\end{tabular}


Table 4 The relationship between risk of malnutrition and sociodemographic characteristics and lifestyle factors

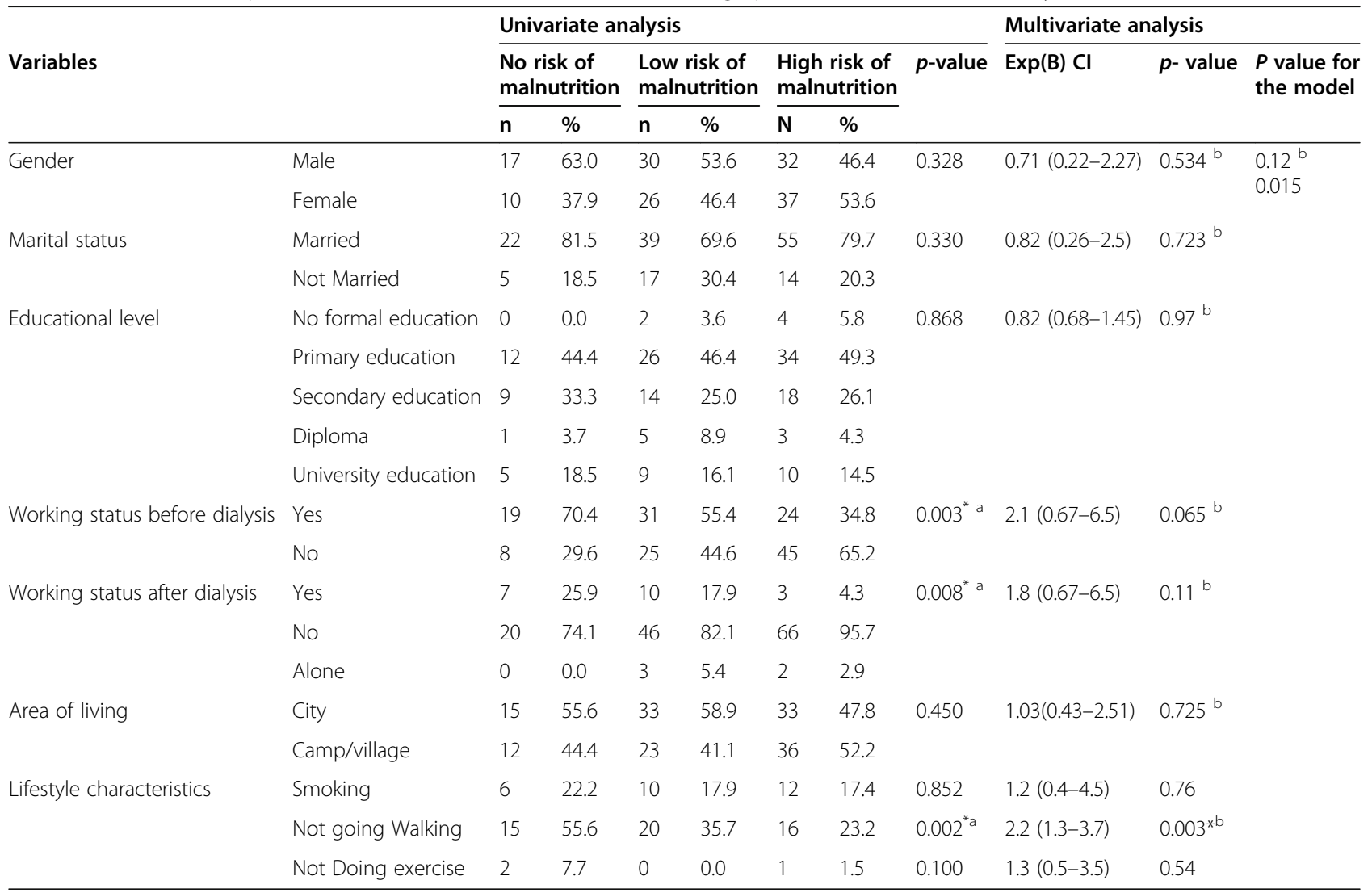

anivariate; ${ }^{\mathrm{b}}$ Multivariate; ${ }^{*}$ Significant at $p$-value $<0.05$ using person chi-square test

who usually walk $(p<0.05)$. On the otherhand, malnutrition was not significantly associated with patients' gender, marital status, educational level, type of housing, and area of living $(p>0.05)$ using Chi-square test. By using Kruskal- Wallis test, we explored that patients' age, watching hours a day, sleeping hours a day, and frequency of doing exercise a week $(p>0.05)$. Our multivariate analysis showed that sociodemographic variables were not a significant predictors of malnutrition. On the contrary, it observed that patients who don't walk have a double risk of being malnourished as compared to patients who walk (Exp (B): 2.2, $p<0.01$, CI: 1.28-3.7) using Binary logistic regression.

\section{Association of medical history and biochemistry parameters with malnutrition risk}

Table 5 shows that patients' serum albumin level and potassium level were significantly correlated with the risk of malnutrition $(p<0.05)$. Furthermore, Table 6 shows that high risk of malnutrition was significantly more predominant among patients with osteoporosis $(47.1 \%)$ compared to those without osteoporosis ( $45.3 \%)$, whereas our multivariate analysis revealed that osteoporosis was not a significant predictor of malnutrition risk.

\section{Relationship of malnutrition and medical history, and nutrition consultation}

The analysis revealed that malnutrition is neither associated with biochemical data nor with the number of comorbidities that a hemodialysis patient is suffering from $(P>0.05)$. Furthermore, it was observed that nutrition consultation, source of nutrition information is not significantly associated with malnutrition $(p>0.05)$.

\section{Correlation between malnutrition and functional status}

Table 7 shows the correlation between malnutrition and functional status (ability to transfer, and ability to do daily activities). A significant relationship was found between malnutrition and ability to ambulate. On the contrary, malnutrition was not associated with ability to transfer, and ability to do daily activities $(p>0.05)$. Our multivariate analysis also revealed that functional status was not a significant predictor of malnutrition risk.

\section{Correlation between malnutrition and hemodialysis side effects, and dietary practices}

Complications during hemodialysis session including; nausea (27.5\%), headache (39.1\%), and hypotension $(40.6 \%)$ were more prevalent in patients with high risk 
Table 5 Relationship between biochemical data and malnutrition categories

\begin{tabular}{llll}
\hline Variables & & Mean \pm SD & $p$-value \\
\hline Serum albumin & No risk of malnutrition & $3.8 \pm 0.6$ & $0.001^{*}$ \\
& Low risk of malnutrition & $3.9 \pm 0.7$ & \\
Total protein & High risk of malnutrition & $3.9 \pm 0.5$ & \\
& No risk of malnutrition & $6.6 \pm 0.8$ & 0.281 \\
& Low risk of malnutrition & $6.6 \pm 0.8$ & \\
Potassium & High risk of malnutrition & $6.8 \pm 0.6$ & \\
& No risk of malnutrition & $4.9 \pm 0.8$ & $0.036^{*}$ \\
Sodium & Low risk of malnutrition & $5.0 \pm 0.9$ & \\
& High risk of malnutrition & $5.0 \pm 1.1$ & \\
& No risk of malnutrition & $134.3 \pm 2.9$ & 0.755 \\
& Low risk of malnutrition & $134.0 \pm 3.4$ & \\
Phosphorous & High risk of malnutrition & $132.6 \pm 14.9$ & \\
& No risk of malnutrition & $5.1 \pm 1.7$ & 0.996 \\
& Low risk of malnutrition & $5.1 \pm 1.3$ & \\
Serignificant at $P$-value $<$ & 0.05 using Kruskal-Wallis test. SD Standard Deviation
\end{tabular}

${ }^{*}$ significant at $P$-value $<0.05$ using Kruskal-Wallis test. SD Standard Deviation of malnutrition than in those with no risk of malnutrition $(p<0.05)$ using ANOVA test. The results also indicate that hemodialysis side effects such as; itching (65.2\%), and access site complications (34.8\%) were more common in participants with high risk of malnutrition than in those with no risk of malnutrition $(p<0.05)$. Binary logistic regression revealed that hypotension during hemodialysis session (Exp B: 2.6, $p<0.05$, CI: 0.84-6.81) and access site infection (Exp (B) :3.4, $p<0.05, \mathrm{CI}: 1.2-14.22)$ were a significant predictor of malnutrition risk. Our findings also indicates that a high risk of malnutrition is more common among patients who didn't feel that the amount of food they eat is enough $(57.1 \%)$ compared to those who felt that the amount of food they eat is enough $(37.4 \%)(p<0.05)$.

\section{Discussion}

In the current study, we targeted to estimate the prevalence of malnutrition among a sample of hemodialysis patients and possible significant predictors of malnutrition among the enrolled patients. Malnutrition is considered a prevalent health issue among hemodialysis patients and is highly associated with mortality and morbidity [4]. Nutritional status is usually disregarded in various hemodialysis centers whereas several ways of nutritional assessment could possibly have an affirmative influence on patient management [25]. Thus, screening of nutritional status and proper nutrition interventions with patients on hemodialysis play a critical role in daily nephrological practice.

The present study demonstrated that approximately half $(45.4 \%)$ of hemodialysis patients at Hebron

Table 6 Relationship between medical history and the risk of malnutrition

\begin{tabular}{|c|c|c|c|c|c|c|c|c|c|c|c|}
\hline \multirow{3}{*}{ Variables } & & \multicolumn{7}{|c|}{ Univariate analysis } & \multicolumn{3}{|c|}{ Multivariate analysis } \\
\hline & & \multicolumn{2}{|c|}{$\begin{array}{l}\text { No risk of } \\
\text { malnutrition }\end{array}$} & \multicolumn{2}{|c|}{$\begin{array}{l}\text { Low risk of } \\
\text { malnutrition }\end{array}$} & \multicolumn{2}{|c|}{$\begin{array}{l}\text { High risk of } \\
\text { malnutrition }\end{array}$} & \multirow[t]{2}{*}{$p$-value } & \multirow[t]{2}{*}{$\operatorname{Exp}(\mathrm{B}), \mathrm{Cl}$} & \multirow[t]{2}{*}{$P$ value } & \multirow[t]{2}{*}{$\begin{array}{l}P \text { value for } \\
\text { the model }\end{array}$} \\
\hline & & $\mathrm{n}$ & $\%$ & $n$ & $\%$ & $\mathrm{~N}$ & $\%$ & & & & \\
\hline \multirow[t]{12}{*}{ Medical history } & Hypertension & 24 & 88.9 & 40 & 71.4 & 59 & 85.5 & 0.070 & $2.6(0.6-10.5)$ & 0.178 & 0.101 \\
\hline & Heart disease & 11 & 40.7 & 19 & 33.9 & 25 & 36.2 & 0.833 & $1.4(0.47-4.2)$ & & \\
\hline & Angina & 3 & 11.1 & 1 & 1.8 & 9 & 13 & 0.076 & $3.9(0.69-15.7)$ & 0.11 & \\
\hline & Diabetes mellitus & 11 & 40.7 & 28 & 50.0 & 32 & 46.4 & 0.729 & $0.9(0.18-1.6)$ & 0.276 & \\
\hline & COPD & 2 & 7.4 & 5 & 8.9 & 12 & 17.4 & 0.246 & $0.87(0.1-5.2)$ & 0.728 & \\
\hline & Asthma & 2 & 7.4 & 5 & 8.9 & 12 & 17.4 & 0.246 & $1.6(0.9-14.6)$ & 0.07 & \\
\hline & Peptic ulcer & 6 & 22.2 & 7 & 12.5 & 7 & 10.1 & 0.285 & $0.6(0.1-3.5)$ & 0.367 & \\
\hline & $\begin{array}{l}\text { Irritable bowel } \\
\text { syndrome }\end{array}$ & 1 & 3.7 & 8 & 14.5 & 10 & 14.5 & 0.308 & $0.6(0.6-3.9)$ & 0.39 & \\
\hline & $\begin{array}{l}\text { Gastroesophageal } \\
\text { reflux disease }\end{array}$ & 3 & 11.1 & 12 & 21.4 & 10 & 14.5 & 0.414 & $0.5(0.1-2.9)$ & 0.394 & \\
\hline & Arthritis & 6 & 22.2 & 20 & 35.7 & 23 & 33.8 & 0.445 & $1.1(0.26-3.21)$ & 0.98 & \\
\hline & Osteoporosis & 0 & 0.0 & 18 & 32.1 & 16 & 23.2 & $0.005^{*}$ & $2.45(0.01-1.9)$ & 0.051 & \\
\hline & History of surgeries & 22 & 88.0 & 47 & 94.0 & 60 & 93.8 & 0.589 & $0.91(0.56-9.8)$ & 0.23 & \\
\hline
\end{tabular}

*Significant at $p$-value $<0.05$ using person chi-square test 
Table 7 The relationship between malnutrition and functional status

\begin{tabular}{llll}
\hline & $\begin{array}{l}\text { No risk of } \\
\text { malnutrition } \\
(\boldsymbol{n}=\mathbf{2 7})\end{array}$ & $\begin{array}{l}\text { Low risk of } \\
\text { malnutrition } \\
(\boldsymbol{n}=\mathbf{5 6})\end{array}$ & $\begin{array}{l}\text { High risk of } \\
\text { malnutrition } \\
(\boldsymbol{n}=\mathbf{6 9})\end{array}$ \\
\hline $\begin{array}{lll}\text { Ability to ambulate } \\
\text { Yes [n (\%)] }\end{array}$ & $5(18.5)$ & $13(23.2)$ & $29(42.0)$ \\
Sometimes [n (\%)] & $0(0.0)$ & $6(10.7)$ & $2(2.9)$ \\
No [n (\%)] & $22(81.5)$ & $37(66.1)$ & $38(55.1)$ \\
Ability to transfer & & & $31(44.9)$ \\
Yes [n (\%)] & $6(22.2)$ & $16(28.6)$ & $4(5.8)$ \\
Sometimes [n (\%)] & $0(0.0)$ & $5(8.9)$ & $34(49.3)$ \\
No [n (\%)] & $21(77.8)$ & $35(62.5)$ & \\
Ability to do daily activities & & & $34(49.3)$ \\
Yes [n (\%)] & $6(22.2)$ & $20(35.7)$ & $10(14.5)$ \\
Sometimes [n (\%)] & $3(11.1)$ & $5(8.9)$ & $25(36.2)$ \\
No [n (\%)] & $18(66.7)$ & $31(55.4)$ & 0.057 \\
\hline
\end{tabular}

*Significant at $p$-value $<0.05$ using person chi-square test

Governmental Hospital at Hebron city, Palestine had a high risk of malnutrition. The prevalence of malnutrition in our sample was generally lower than that reported in previous studies including; Egypt (67\%) [25], Baghdad (63.5\%) [26], Jordan (62\%) [27], and Jeddah (55\%) [28]. On contrary, the prevalence of malnutrition among our sample was slightly higher than that reported in a former study conducted in Riyadh [29]. These variations in malnutrition prevalence are attributed to and diverse diet regimens and environmental variety in middle east region [25].

Our research confirmed that the existence of certain diseases, especially osteoporosis has a significant influence on patients' nutritional status as assessed by renal iNUT score. Malnutrition is an important risk factor for osteoporosis in patients undergoing hemodialysis [30]. Secondary hyperparathyroidism is a frequent complication of chronic kidney disease and it is caused due to decreased vitamin D synthesis, parathyroid (PTH) skeletal resistance, hyperphosphatemia, as well as hypocalcemia. The immoderate secretion of PTH in patients with renal failure leads to high bone turnover [31].

Our study showed malnutrition is not correlated with the level of education among hemodialysis patients. This finding is inconsistent with a former Saudi Arabian study, which is found that un educated patients had a higher risk of malnutrition compared to highly-educated patients [28]. The current findings also pointed out that patients' gender has no effect on the nutritional state of patients. Similar findings regarding gender were observed in a Palestinian study [32], and an Iraqi study [26].

In contrast to a Romanian study [33], and a former Palestinian study [32], our study showed that patients' age has no effect on nutritional status of hemodialysis patients. Moreover, our results figured out that high risk of malnutrition was significantly more common among unemployed patients compared to their counterparts. This result was supported by a former Palestinian study conducted by Abu Rezeq et al. [32], where it was found that employed patients had significantly greater SGA score which indicates for a bestead nutritional state.

According to the current study, functional status is one of the predictors that have significant relationship with high risk of malnutrition. Our analysis indicates that high risk of malnutrition was significantly more predominant among hemodialysis patients who are not able to ambulate $(55.1 \%)$ compared to those who are unable to ambulate $(42.0 \%)$. This finding was in agreement with a former research which has found that malnourished patients had lower functional status in comparison to their well-nourished counterparts [34]. Furthermore, in a former study conducted by Abdulan et al. [35], it was indicated that malnutrition scores could be a useful way in predicting severe functional impairment.

Furthermore, our findings reveal that high risk of malnutrition were significantly more prevalent in patients who did not walk compared to their counterparts who usually walk. This finding robustly goes in agreement with the hypothesis that malnutrition and reduced protein metabolism accompanied with increased catabolism sturdily effect the capability of patients on hemodialysis to carry out physical activities [36].

Moreover, it was found that complications during hemodialysis session such as nausea, headache, and hypotension were more prevalent in patients with high risk of malnutrition than in those with no risk of malnutrition. The results also indicate that hemodialysis side effects such as; itching, and access site complications 
were more common in participants with high risk of malnutrition than in those with no risk of malnutrition. In addition, our findings indicates that a high risk of malnutrition is more common among patients who didn't feel that the amount of food they eat is enough compared to those who felt that the amount of food they eat is enough. The relationship between these variables and malnutrition has not yet been discovered before.

\section{Limitations}

Results of the current research must be considered in the framework of its design limitations. First, the major limitation of the current study resides in its design. Being cross-sectional, it's impossible to derive a causeeffect relationship. Second, the study was limited to hemodialysis patient at Hebron Governmental Hospital and does not exemplify the overall hemodialysis patients' category in Palestine. Third, inflammatory markers were also required to be extracted in order to have better overall clinical status of the patients and with a view to ease the interpretation of albumin level differences. Fourth, dietary assessment was not included in the study. Finally, Secondly, we have used self-reporting methods which increases the risk of respondent error. Regardless of these limitations, our research will give indicative marks to health professionals towards the nutritional status among patients on hemodialysis and the necessity for consultation in hemodialysis centers in Palestine.

\section{Conclusions}

Screening the nutritional status in patients on hemodialysis is a fundamental issue and necessitate to be pursued by a team of health professionals in hemodialysis centers. This research showed an increased prevalence of malnutrition among hemodialysis patients at Hebron Governmental Hospital, therefore the nutritional status of patients on hemodialysis requires more alertness by renal dietitians and constant education, nutrition counseling, and nutrition assessment. Furthermore, findings indicate that osteoporosis, walking, certain hemodialysis side effects (e.g., itching and access site complications), and complications during hemodialysis session (e.g., headache, nausea, hypotension) are significantly associated with malnutrition. There is an urgent necessity to expand the research to further Palestinian hospitals. At last, there is a necessity to pursue the research prospectively to uncover a cause-effect relationship.

\section{Acknowledgements}

We would like to acknowledge the students who helped the researchers in the data collection. We would like to express our gratitude to hemodialysis patients who agreed to participate in this study. Thanks, are also to all coresearchers and fieldworkers involved in this study.

\section{Authors' contributions}

The authors have contributed in the manuscript as the following; Manal Badrasawi: the principal investigator has written the study proposal and protocol and drafted the research paper. Souzan Zidan has the responsibility for the research data management and final manuscript writing. Israa, Juliana, Sanabel, Tala, Yasmeen have helped in the proposal writing, data collection, data entry, data analysis and wrote the literature review. All authors have read and approved the final manuscript.

\section{Funding}

The authors declare that no external financial support was received for this study.

Availability of data and materials

The dataset used and analysed in this study is available from corresponding Author on reasonable request.

\section{Declarations}

\section{Ethics approval and consent to participate}

The research protocols were in accordance with Declaration of Helsinki and reported in line with the STROBE checklist for reporting cross-sectional studies. The protocol was approved by the Deanship of Scientific Research Ethical Committee at Palestine Polytechnic University. Permissions and approval to conduct the study were obtained from the Palestinian Ministry of Health. Informed written and verbal consents have been collected from al participants prior to data collection.

Consent for publication

Not Applicable.

\section{Competing interests}

The authors declare they have no competing interests.

\section{Author details}

${ }^{1}$ Department of Nutrition and Food technology, Faculty of Agriculture and Veterinary medicine, An-Najah National University, Nablus, West Bank, Palestine. ${ }^{2}$ Department of Nutrition and Food technology, Faculty of Agriculture, Hebron university, Hebron, West Bank, Palestine. ${ }^{3}$ Healthy and Therapeutic Nutrition Department, Faculty of Medicine and Health Sciences, Palestine Polytechnic University, Hebron, Palestine.

Received: 12 March 2021 Accepted: 12 May 2021

Published online: 07 June 2021

\section{References}

1. Shyam CV Sreenivas V. Chronic kidney disease: a missing component of integrated control of non-communicable diseases. Indian J Med Res. 2005; 122(5):451-3.

2. Collins AJ, Foley RN, Herzog C, Chavers B, Gilbertson D, Herzog C, Agodoa, L. (2013). US Renal Data System 2012 Annual Data Report. Am J Kidney Dis. 2013; 61(1 Suppl 1): A7, e1-476.

3. Health Annual Report, Palestine 2019. Retrieved from; HYM2UGrm8hFDOPe1AW6z2W6ZDvbJbuYGykdfV6B1IEulthrx5QMAyC 5WFKDTWWGKW307rk4vgIUzRIhJdSYyQXxFKscP6Uqz3UhrxoWLCHIT.pdf (moh.ps)

4. Dukkipati R, Kopple JD. Causes and Prevention of Protein-Energy Wasting in Chronic Kidney Failure. Semin Nephrol. 2009; 29(1):39-49.

5. de Mutsert R, Grootendorst DC, Boeschoten EW, Brandts H, van Manen GJ, Krediet RT, Dekker FW, Netherlands Cooperative Study on the Adequacy of Dialysis-2 Study Group. Subjective global assessment of nutritional status is strongly associated with mortality in chronic dialysis patients. Am J Clin Nutr. 2009; 89(3):787-93.

6. Chung S, Koh ES, Shin SJ, Park CW. Malnutrition in patients with chronic kidney disease. Open Journal of Internal Medicine. 2012; 2(2): 89-99.

7. Lacquaniti A, Bolignano D, Campo S, Perrone C, Donato V, Fazio MR., Buemi A, Sturiale A, Buemi M. Malnutrition in the Elderly Patient on Dialysis. Ren Fail. 2009:31(3):239-45.

8. Jackson HS, MacLaughlin HL, Vidal-Diez A, Banerjee D. A New Renal Inpatient Nutrition Screening Tool (Renal iNUT): A Multicenter Validation Study. Clin Nut. 2019; 38(5):2297-2303. 
9. Neyra R, Chen K, Sun M, Shyr Y, Hakim R, Ikizler T. Increased resting energy expenditure in patients with end-stage renal disease. J Parenter Enteral Nutr. 2003; 27(1): 36-42.

10. Nakashima A, Ohkido I, Yokoyama K, Mafune A, Urashima M, Yokoo T. Associations Between Low Serum Testosterone and All-Cause Mortality and Infection-Related Hospitalization in Male Hemodialysis Patients: A Prospective Cohort Study. Kidney Int Rep. 2017; 2(6):1160-1168.

11. Price SR, Gooch JL, Donaldson SK, Roberts-Wilson TK. Muscle Atrophy in Chronic Kidney Disease Results from Abnormalities in Insulin Signaling. Ren Nutr. 2010; 20(5 Suppl): S24-8.

12. Wang $\mathrm{H}$, Ye J. Regulation of energy balance by inflammation: Common theme in physiology and pathology. Rev Endocr Metab Disord. 2015; 16(1): 47-54.

13. Carrero JJ, Qureshi AR, Axelsson J, Yilmaz MI, Rehnmark S, Witt MR, Bárány B, Heimbürger O, Suliman ME, Alvestrand A, Lindholm B, Stenvinkel P. Clinical and biochemical implications of low thyroid hormone levels (total and free forms) in euthyroid patients with chronic kidney disease. J Intern Med. 2007; 262(6):690-701.

14. De Brito-Ashurst I, Varagunam M, Raftery MJ, Yaqoob MM. Bicarbonate Supplementation Slows Progression of CKD and Improves Nutritional Status J Am Soc Nephrol.2009; 20(9):2075-84..

15. Pupim LB, Heimburger O, Qureshi AR, Ikizler T. Alp, Stenvinkel, P. Accelerated lean body mass loss in incident chronic dialysis patients with diabetes mellitus. Kidney Int. 2005; 68(5): 2368-2374.

16. Kurella Tamura M, Covinsky KE, Chertow GM, Yaffe K, Landefeld CS, McCulloch CE. (2009). Functional Status of Elderly Adults before and after Initiation of Dialysis. N Engl J Med. 2009; 361(16):1539-47.

17. Kalantar-Zadeh K, Ikizler TA, Block G, Avram MM, Kopple JD. Malnutritioninflammation complex syndrome in dialysis patients: causes and consequences. Am J Kidney Dis. 2003; 42(5):864-81.

18. Jassal SV, Karaboyas A, Comment LA, Bieber BA, Morgenstern H, Sen A, Gillespie BW, De Sequera P, Marshall MR, Fukuhara S, Robinson BM, Pisoni RL, Tentori F. Functional Dependence and Mortality in the International Dialysis Outcomes and Practice Patterns Study (DOPPS). Am J Kidney Dis. 2016; 67(2):283-92.

19. Yamagata K, Hoshino J, Sugiyama H, Hanafusa N, Shibagaki Y, Komatsu Y, ... Kohzuki M. Clinical practice guideline for renal rehabilitation: systematic reviews and recommendations of exercise therapies in patients with kidney diseases. Renal Replacement Therapy.2019; 5(1).

20. Alp Ikizler T, Cano NJ, Franch H, Fouque D, Himmelfarb J, Kalantar-Zadeh K, ... Wanner C. Prevention and treatment of protein energy wasting in chronic kidney disease patients:a consensus statement by the International Society of Renal Nutrition and Metabolism.Kidney Int. 2013; 84(6):1096 - 107

21. Lohr SL. Sampling: Design and Analysis (2nd ed.). Boston: Brooks/Cole. 2010

22. Lee RD, Nieman DC. (2007). Nutritional Assessment: McGraw-Hill Higher Education.

23. WHO. Body Mass index - report. 2018. http:// Cut-off for BMI according to WHO standards - European Health Information Gateway. Assessed on 19.02.2021.

24. Shah S, Leonard AC, Thakar CV. (2018). Functional status, pre-dialysis health and clinical outcomes among elderly dialysis patients. BMC Nephrol. 2018; 19(1):100.

25. Zaki DSD, Mohamed RR, Mohammed NAG, Abdel-Zaher RB. Assessment of Malnutrition Status in Hemodialysis Patients. Clinical Medicine and Diagnostics. 2019; 9(1): 8-13.

26. Al-Saedy AJ, Al-Kahichy HR. The current status of hemodialysis in Baghdad. Saudi J Kidney Dis Transpl. 2011; 22(2): 362-367.

27. Tayyem RF, Mrayyan MT, Heath DD, Bawadi HA. Assessment of Nutritional Status Among ESRD Patients in Jordanian Hospitals. J Ren Nutr. 2008; 18(3):281-7.

28. Alharbi K, Enrione EB. Malnutrition is prevalent among hemodialysis patients in Jeddah, Saudi Arabia. Saudi J Kidney Dis Transpl. 2012; 23(3):598-608.

29. Al-Saran KA, Elsayed SA, Molhem AJ, AIDrees AS, AIZara HM. Nutritional assessment of patients in a large Saudi dialysis center. Saudi Med J. 2009; 30(8):1054-1059.

30. Ito M, Tanaka S. Bone disorder and nutrition. Clin Calcium. 2016; 26(3):375-83.

31. Yuen NK, Ananthakrishnan S, Campbell MJ. Hyperparathyroidism of Renal Disease. Perm J. 2016; 20(3):15-127.

32. Abu Rezeq H, Khdair LN, Hamdan ZI, Sweileh WM. Prevalence of Malnutrition in Hemodialysis Patients: A Single-Center Study in Palestine. Saudi J Kidney Dis Transpl. 2018; 29(2):332-340.
33. Segall L, Mardare NG, Ungureanu S, Busuioc M, Nistor I, Enache R, Marian Simona, Covic A. Nutritional status evaluation and survival in haemodialysis patients in one center from Romania. Nephrol Dial Transplant. 2009; 24(8): 2536-2540.

34. Laws RA, Tapsell LC, Kelly J. Nutritional status and its relationship to quality of life in a sample of chronic hemodialysis patients. J Ren Nutr. 2000; 10(3): 139-147.

35. Abdulan IM, Onofriescu M, Stefaniu R, Mastaleru A, Mocanu V, Alexa I-D, Covic A. The predictive value of malnutrition for functional and cognitive status in elderly hemodialysis patients. Int Urol Nephrol. 2019; 51(1):155-162.

36. Zamojska S, Szklarek M, Niewodniczy M, Nowicki M. Correlates of habitual physical activity in chronic haemodialysis patients. Nephrol Dial Transplant. 2006; 21(5):1323-1327.

\section{Publisher's Note}

Springer Nature remains neutral with regard to jurisdictional claims in published maps and institutional affiliations.
Ready to submit your research? Choose BMC and benefit from:

- fast, convenient online submission

- thorough peer review by experienced researchers in your field

- rapid publication on acceptance

- support for research data, including large and complex data types

- gold Open Access which fosters wider collaboration and increased citations

- maximum visibility for your research: over $100 \mathrm{M}$ website views per year

At $\mathrm{BMC}$, research is always in progress.

Learn more biomedcentral.com/submissions 